\title{
Frequency of Fine Needle Aspiration Cytological Category C5 in Breast Lesions among Females of Various Age Groups
}

\author{
SADIA YASEEN ${ }^{1}$, MUDASSAR ALI ${ }^{2}$, FAHEEM MAHMOOD ${ }^{3}$, SAHAR MUDASSAR $^{4}$, UMBER NISAR $^{5}$ \\ ${ }^{1}$ Assistant Professor of Medical Education, Rashid Latif Medical College, Lahore \\ ${ }^{2}$ Associate Professors of Physiology, Rashid Latif Medical College, Lahore \\ ${ }^{3}$ Associate Professors of Physiology, Rashid Latif Medical College, Lahore \\ ${ }^{4}$ Associate Professor of Pathology, Rashid Latif Dental College, Lahore \\ ${ }^{5}$ Assistant Professor, Department of Computer Sciences, Forman Christian College University, Lahore \\ Correspondence to: Dr. Sadia Yaseen, E-mail: sadiaali651@gmail.com, Cell: 0304-4865739
}

\begin{abstract}
Background: Benign as well as malignant neoplasm of breast still appears to be the prime tumour among females and the prevalence of the disease is increasing all over the countries. The likelihood of emergence of breast neoplasm is linked to a number of factors i.e. reproductive life events and the factor of lifestyle that modify levels of endogenous sex hormones. One of most important risk factors is growing old age. Fine needle aspiration cytology (FNAC) is a least traumatic, reliable simple, complication free technique and economical for the diagnosis of mass lesions. It can be easily repeated if an adequate aspirate is not obtained.

Aim: To determine the frequency of cytological category of FNAC C5 of breast lesion among different age groups.

Study Design: Cross sectional comparative research study

Place and Duration of Study: Department of Histopathology, Shaikh Zayed Hospital, Lahore from $21^{\text {st }}$ January 2016 to $22^{\text {nd }}$ September 2016.

Methodology: One hundred and twenty female patients selected who presented with complain of palpable lesion in breast and was correlated with physical examination recording the size and consistency of mass. The procedure was performed on patients with complete clinical and radiological work up. After preparation of direct smear, slides were processed according to routine processing and then stained with H\&E and Giemsa.

Results: Thirty (25.80\%) were between 18-30 age group while $42(35.00 \%), 47(39.20 \%)$ were between $31-45$ and 46-60 age groups respectively. Though majority of FNAC cases were found in age group 31-45 but there was no significant difference among three groups by age.

Conclusion: Malignancy in palpable breast masses can surely be diagnosed by a combination of clinical examination of breast and FNAC which when performed by a dedicated cytopathologist should be an integral part of a breast screening service. Middle age group had highest frequency but difference was insignificant.

Keywords: Fine needle aspiration cytology, Palpable breast lesions, Age groups
\end{abstract}

\section{INTRODUCTION}

Breast diseases are very common in females and range from inflammatory lesions to benign and invasive carcinomas. ${ }^{1}$ Pakistan has a significant cancer burden. It has been estimated that about 40,000 patients die every year due to breast cancer alone and $90 \%$ of these cancers can be cured if detected early. There are no national cancer screening programmes that can educate people about cancer screening and early detection. ${ }^{2}$ In Asian countries; Pakistan is bearing the highest load of breast cancer patients. Even Young females also present at late stages of breast cancer, with a negative impact on prognosis. $^{3}$

The continued vigilance and earlier diagnosis of any lesion in breast can help in decreasing the incidence of invasive carcinomas. ${ }^{4}$ But in Pakistan women ignore their health problems including breast cancer due to many factors. Most important of these are hesitancy of women to be examined themselves from male physicians and lack of mutual understanding with spouse to discuss about breast cancer. ${ }^{5}$

Inflammatory lesions are common in lactating females. Benign tumours are frequent in young adults and malignant tumours are common in older females. Breast diseases are mostly confined to females not only for the hormonal influence but also of their more complex structure and greater volume, whereas male breasts are rudimentary non-functional organs, relatively insensitive to endocrine stimuli and apparently resistant to neoplastic growth. ${ }^{6}$

Most breast diseases present as a palpable lump, mastalgia and nipple discharge. Although most lumps are benign but the neoplasm constitutes the most important lesions of the female breasts. Due to increased public awareness about cancer, the appearance of a lump causes great concern to the patient. Evaluation and diagnosis of breast diseases involves the triple assessment that is clinical history and examination, radiological imaging and tissue sample taken for either cytological or histological analysis.

Ultrasonography and mammography, fine needle aspiration cytology (FNAC) and core biopsy are the investigations of choice for diagnosis of majority of breast conditions but excisional biopsy remains the gold standard for diagnosis. ${ }^{7}$

Numerous studies have been done on carcinoma of the breast but studies on the general pattern of breast diseases in female population are limited. ${ }^{8}$ There is a dearth of such studies in our country and there exists a need to know the incidence of different types of breast diseases so that guidelines for prevention, early detection and treatment can be developed. 
Fine needle aspiration cytology is easiest and economical diagnostic modality for the diagnosis of breast lesions and for categorization of breast lesions, a five tier system (C1-C5) is being used all over the world with categories ranging from insufficient materials (C1), benign (C2), atypical (C3), suspicious of malignancy (C4), or frankly malignant (C5).

Cytological categorization initiative was taken by National Coordinating Committee for Breast Screening and National Breast Screening Program of UK. It has been introduced into practice as a guide to report the results of aspiration cytology by fine needle into a five tier categorization to ease the understanding of diagnosis for surgeon as well as patient. ${ }^{9}$

\section{MATERIALS AND METHODS}

This cross sectional comparative study was carried out at Histopathology Department, Shaikh Zayed Medical complex, Lahore from $21^{\text {st }}$ January 2016 to $22^{\text {nd }}$ September 2016. A total of 120 patients selected who presented with complain of palpable lesion in breast and was correlated with physical examination recording the size and consistency of mass. The size of breast mass was measured in length by measuring tape. The tumour size was measured by measuring tape. Females of age eighteen to sixty years old with palpable mass of breast were included. Female patients who didn't give consent, diagnosed already and impalpable masse were the exclusion criteria. For FNA procedure disposable $10 \mathrm{cc}$ syringe of needle gauge 22 was used. Patient's name with glass marker was labelled on clean glass slides. A 95\% alcohol fixative was used and H\&E and Giemsa were used to stain the slides (Fig.1).

Patient was informed about procedure in detail before performing it and a proper verbal and written consent was taken. Procedure was performed on patients with complete clinical and radiological work up. Palpation of the breast mass was carried out in all cases to locate the breast lesion, to feel its consistency, size and extent of the mass, so that aspirate could be taken should not miss the cytology of lesion. Between left thumb and the index finger, mass was held. The skin area over the lesion and surrounding was sterilized with spirit three attempts were done by syringe to have ample aspirate to ease diagnosis. Needle of syringe was entered in breast lesion after clinical assessment and suction was applied. Needle and barrel of syringe was moved in and out so that enough aspirate was obtained. The suction caused by plunger was set free when the aspirate i.e. blood or material is found in the needle hub.

Droplets of aspirate were added onto glass slide and spread over it. After preparation of direct smear, slides were processed according to routine processing and then stained with H\&E and Giemsa. Skin where FNA was performed was pressed and bandage done. Slides were examined under microscope.

Data were entered and analyzed by using SPSS-20. Chi-square test was used to compare FNAC C5 among three age groups. P-value $\leq 0.05$ was considered significant.

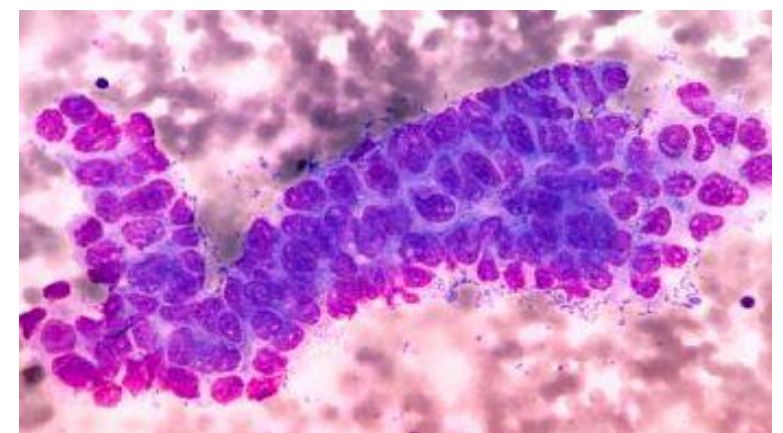

Fig. 1: C5 cytological category showing hyperchromatic polymorphic malignant breast cells ( $40 \mathrm{X}$ objective)

\section{RESULTS}

All patients had lumps 120 (100.0\%) while 2 (1.7\%) had the complication of nipple discharge. One hundred and fifteen $(95.8 \%)$ had unilateral breast lesion. Among these 21 $(17.5 \%)$ had the consistency of lesion as cystic, and remaining solid. Thirty two of these were categorized as C5 on FNAC (Table 1)

The maximum percent of C5 category was in age group $31-45$ years with $33.3 \%$ cases. The group with age $18-30$ had $22.6 \%$ while $46-60$ had $23.4 \%$ of C5 cases with average age was $39.96 \pm 12.23$ years ranging between 18 and 60 years. This difference between ages was though found insignificant with p-value 0.485 (Table 2).

Table 1: Basic characteristic of lesions

\begin{tabular}{|l|l|l|l|l|}
\hline \multirow{2}{*}{ Characteristic } & Yes & No \\
\cline { 2 - 5 } & No. & $\%$ & No. & $\%$ \\
\hline Lump & 120 & 100.0 & 0 & 0.0 \\
\hline $\begin{array}{l}\text { Complication of nipple } \\
\text { discharge }\end{array}$ & 2 & 1.7 & 118 & 98.3 \\
\hline Bilateral & 5 & 4.2 & 115 & 95.8 \\
\hline Consistency Cystic & 21 & 17.5 & 99 & 82.5 \\
\hline FNAC C5 & 32 & 26.7 & 88 & 73.3 \\
\hline
\end{tabular}

Table 2: Comparison of FNAC C5 category between different age groups

\begin{tabular}{|l|l|l|l|l|l|l|}
\hline \multirow{2}{*}{$\begin{array}{l}\text { Age } \\
\text { (years) }\end{array}$} & C5 & Other & \multicolumn{2}{|l|}{ Total } \\
\cline { 2 - 7 } & No. & $\%$ & No. & $\%$ & No. & $\%$ \\
\hline $18-30$ & 7 & 22.6 & 24 & 77.4 & 31 & 100.0 \\
\hline $31-45$ & 14 & 33.3 & 28 & 66.7 & 42 & 100.0 \\
\hline $46-60$ & 11 & 23.4 & 36 & 76.6 & 47 & 100.0 \\
\hline Total & 32 & 100.0 & 88 & 100.0 & 120 & 100.0 \\
\hline
\end{tabular}

\section{DISCUSSION}

The fine needle aspiration cytology (FNAC) has achieved great importance in diagnosis and management of palpable breast lesions. Due to simplicity, safety, and diagnostic accuracy, this procedure has become a widely used adjuvant diagnostic technique in management of breast lumps. ${ }^{10-12}$

The National Cancer Institute recommends five categories for diagnosis of breast aspiration cytology ${ }^{13}$ in order to bring a degree of uniformity to the diagnostic reporting. These categories are unsatisfactory $(\mathrm{C} 1)$, benign lesion (C2), atypical, probably benign (C3), suspicious, probably malignant (C4), and malignant (C5). 
In this study, out of 32 FNAC C5 category, 7(21.9\%) were between $18-30$ age group, while $14(43.8 \%)$, $11(34.4 \%)$ were between $31-45$ and $46-60$ age groups respectively.

In a retrospective study at the Armed Forces Institute of Pathology, Rawalpindi, the mean age of all breast cancers was $28 \pm 2.7$ years. FNAC C5 category was most frequent in 26-30 years' age group (78.6\%). ${ }^{14}$ In another study carried out at Banaras Hindu University, India, 1315 breast lesions in women up to 40 years of age were analyzed and out of these 508 lesions were C5 category $(38.6 \%) .^{15}$

The results of our study are further strengthened by a cross sectional study carried out in Tehran from 1996 to 2000, wherein Hirarchi et $\mathrm{al}^{16}$ showed that the highest frequency $(31.8 \%)$ of C5 category was in the $40-49$ age group. $23 \%$ of breast cancers in women younger than 40 years.

In a study carried out in China by Kwong et al ${ }^{17}$, $17.6 \%$ of the Chinese women with C5 category were younger than 40 years of age. Similarly a study carried out in Yemen in 1998 showed that age groups mostly affected by $C 5$ category were $30-39$ years and $40-49$ years. ${ }^{18}$

The results of our study are similar to a multinational, collaborative, retrospective survey aimed at studying the overall picture of C5 category in three Asian regions, Lucknow and Mumbai in India, Kaula Lumpur in Malaysia and Hong Kong, with an emphasis on the picture in young women (<35years of age).

In that study, $26 \%$ of the patients with C5categoryatLucknow were younger than 35 years of age with peak incidence in the age group 35-40. Data from Mumbai and Kaula Lumpur showed $11 \%$ and $7.6 \%$ of patients with $\mathrm{C} 5$ category amongst younger than 35 years of age, respectively. Data from other countries showed that $7.4 \%$ of American patients, $29.3 \%$ of Taiwanese, $12.6 \%$ of Singaporean and $8 \%$ of Australian with C5 category were under 35 years of age. ${ }^{19}$

\section{CONCLUSION}

Malignancy in palpable breast lesions can definitely be diagnosed by a combination of physical examination and FNAC which when performed by a dedicated cytopathologist should be an integral part of a breast screening service. Risk of malignancy category C5 may increase with increasing age.

\section{REFERENCES}

1. Aslam HM, Saleem S, Shaikh HA, Shahid N, Mughal A, Umah R. Clinico-pathological profile of patients with breast diseases. Diagnostic Pathol 2013;8:77.
2. Sharif MA, Mamoon N, Mushtaq S, et al. Steroid hormone receptor association with prognostic markers in breast carcinoma in Northern Pakistan. J Coll Physicians Surg Pak 2010; 20: 181-5.

3. Menhas R, Umer S. Breast Cancer among Pakistani Women. Iranian J Public Health 2015; 44(4):586-587.

4. Tiwari M. Role of fine needle aspiration cytology in diagnosis of breast lumps. Kathmandu University MedJ2007; 5: 215-7.

5. Ayaz F, Ayaz SB, Farrukh M. Reasons for delayed presentation of women with breast cancer. J Islamabad Med Dent Coll 2016; 5(4):187-91.

6. Riaz S, Jalil S, Shakoor A, Suleman BA. Frequency and distribution of different types of breast carcinoma. Esculapio 2008; 4(3): 29-31.

7. Bhurgri $\mathrm{Y}$, Kayani N, Faridi N, et al. Pathoepidemiology of breast cancer in Karachi '1995-1997'. Asian Pac J Cancer Prev 2007; 8:215-20.

8. Talpur AA, Surahio AR, Ansari AG, Ghumro AA. Late presentation of breast cancer: a dilemma. J Pak Med Assoc 2011; 61(7): 662-6.

9. Mendoza P, Lacambra M, Tan P-H, Tse GM. Fine needle aspiration cytology of the breast: the non-malignant categories. Pathol Res Int 2011;2011:547580.

10. Nguansangiam $S$, Jesdapatarakul $S$, Tangjitgamol $S$. Accuracy of fine needle aspiration cytology from breast masses in Thailand. Asian Pac J Cancer Prev 2009; 10(4):623.

11. Akçil M, Karaağaoğlu E, Demirhan B. Diagnostic accuracy of fine-needle aspiration cytology of palpable breast masses: an SROC curve with fixed and random effects linear metaregression models. Diagnostic Cytopathol 2008;36(5):30310.

12. Berner A, Davidson B, Sigstad E, Risberg B. Fine-needle aspiration cytology vs. core biopsy in the diagnosis of breast lesions. Diagnostic Cytopathol 2003;29(6):344-8.

13. Bibbo M, Abati A, Ferenczy A, Robitaille J, Franco E, Arseneau $\mathrm{J}$, et al. The uniform approach to breast fine needle aspiration biopsy. Acta Cytologica 1996;40(6):11206.

14. Mamoon N, Hassan U, Mushtaq S. Breast carcinoma in young women aged 30 or less in Northern Pakistan-the Armed Forces Institute of Pathology experience. Asian Pacific J Cancer Prevention 2009;10:1079-82.

15. Khanna R, Khanna S, Chaturvedi S, Arya NC. Spectrum of breast disease in young females: a retrospective study of 1315 patients. Indian J Pathol Microbiol 1998;41(4):397-401.

16. Harirchi I, Karbakhsh M, Kashefi A, Momtahen AJ. Breast cancer in Iran: results of a multi-center study. Asian Pacific $\mathrm{J}$ Cancer Prevention 2004;5(1):24-7.

17. Kwong A, Cheung $P$, Chan S, Lau S. Breast cancer in Chinese women younger than age 40: are they different from their older counterparts? World J Surg 2008;32(12):2554.

18. Hamid GA, Tayeb MS, Bawazir AA. Breast cancer in southeast Republic of Yemen. East Mediatr Health J 2001; 7(6): 1012-6.

19. Agarwal G, Pradeep PV, Aggarwal V, Yip CH, Cheung PS Spectrum of breast cancer in Asian women. World J Surg 2007;31(5):1031-40. 